\title{
HISTORIA, NATURALEZA Y MEMORIA EN VIAJE A LA SEMILLA
}

\author{
POR \\ WILLIAM LUIS \\ Washington University
}

En 1943 Alejo Carpentier viaja a Haití donde presencia lo real maravilloso, la unión de Africa y Europa, lo que para él caracterizaria el Caribe y América. El viaje influye en la escritura carpenteriana de los años cuarenta'. Un año después, en 1944, Carpentier publica "Viaje a la semilla", cuento que incorpora elementos de su experiencia en la isla hai tiana. Más tarde, en 1949, esa misma experiencia se convierte en el tema principal de su novela $\mathrm{El}$ reino de este mundo. Sin duda, hay una relación estrecha entre el viaje, el cuento y la novela. En 1964 Carpentier escribiría:

\begin{abstract}
Por ello diré que una primera noción de lo real maravilloso me vino a la mento cuando, a fines del año 1943, tuve la suerte de poder visitar el reino de Henri Christophe-las ruinas tan poeticas, de Sans-Souci; la mole, imponentemento intacta a pesar de rayos y terremotos, de la Ciudadela La Ferrière- y de conocer la todavía normanda Ciudad del Cabo, el Cap Français de la antigua Colonia, donde una casa de larguísimos balcones conduce al palacio de cantería habitado antaño por Paulina Bonaparte. Mi encuentro con Paulina Bonaparte, ahf, tan lejos de Córcega, fue para mí, como una revelación. Vi la posibilidad de establecer ciertos sincronismos posibjes, americanos, recurrentes, por encima del tiempo, relacionando esto con aquello, el ayer con el presente. Vî la posibilidad de traer ciertas verdades europeas a las latitudes que son nuestras actuando a contrapelo de quienes, viajando contra la trayectoria del sol, quisieron llevar verdades nuestras a donde, hace todavía treinta años, no había capacidad de entendimiento ni de medida para verlas en su justa dimensión ${ }^{2}$.
\end{abstract}

\footnotetext{
${ }^{3}$ Aunque ya se ha postulado que Carpentier escribió sus cuentos mientras preparaba $L a$ música en Cuba, [Véase por cjemplo, Roberto González Echevarría, Alejo Carpenlier: The Pilgrim al Home (Ithaca, NY: Cornell University Press, 1977) 101-107] nosotros pensamos que el viaje a Haití no sólo contribuyó al libro de Carpentier sino también a la escritura de algu nos cuentos y, como se sabe, a El reino de este mundo.

${ }^{2}$ Tienlos y diferencias (Montevideo: Arca, 1967) 113-14. También citado por Manuel Durán en su "Viaje a la semilla: el cómo y el porqué de una pequeña obra maestra", en Asedios a Carpentier (Santiago de Chile: Editorial Universitaria, 1972) 214, nota 3.
} 
Si Derrida propone que el mundo occidental se desplaza de un origen ausente ${ }^{3}$, Carpentier, siguiendo las ideas desarrolladas por los surrealistas, nota que Africa, o por lo menos la cultura africana en Haití, contiene su propio origen, que se ajusta a los ciclos de la naturaleza. La novela y el cuento incorporan dos tiempos: uno es cronológico y se asocia con el reloj y el mundo occidental; el otro se contrapone a éste, y responde a un origen africano de armonia entre el hombre y las cosas.

La contraposición de Europa y Africa está presente en "Viaje a la semilla", pero Carpentier desarrolla este tema con más profundidad en El reino de este mundo. La tensión entre los dos mundos se revela en la doble interpretación de la muerte de Mackandal. Una se explica de acuerdo con la tradición occidental y la otra con la religión africana:

Mackandal estaba ya adosado al poste de torturas. El verdugo había agarrado un rescoldo con las tenazas. Repitiendo un gesto estudiado la vispera frente al espejo, el gobernador desenvainó su espada de corte y dio orden de que se cumpliera la sentencia. El fuego comenzó a subir hacia el manco, sollamándole las piernas. En ese momento, Mackandal agitó su muñón que no habían podido atar, en un gesto conminatorio que no por menguado era menos terrible, aullando conjuros desconocidos y echando violentamente el torso hacia adelante. Sus ataduras cayeron, y el cuerpo del negro se espigo en el aire, volando por sobre las cabezas, antes de hundirse en las ondas negras de la masa de esclavos. Un solo grito llenó la plaza: ¡Mackandal sauvé! Y fue la confusión y el estruendo: Los guardias se lanzaron, a culatazos, sobre la negrada aullante, que ya no parecía caber entre las casas y trepaba hacia los balcones. Ya tanto llegó el estrépito y la grita y la turbamulta, que muy pocos vieron que Mackandal, agarrado por diez soldados, era metido de cabeza en el fuego, y que

\footnotetext{
${ }^{3}$ Dice Derrida: "The value of the transcendental arche [archie] must make its necessity felt before letting itself be crased. The concept of arche-trace must comply with both that necessity and that erasure. It is in fact contradictory and not acceptable within the logic of identity. The trace is not only the disappearance of origin -within the discourse that we sustain and according to the path that we follow it means that the origin did not ever disappear, that it was never constituted except reciprocally by a nonorigin, the trace, which thus becomes the origin of the origin. From then on, to wrench the concept of the trace from the classical scheme, which would derive it from a presence or from an originary nontrace and which wou ld make of it an empirical mark, one must indecd speak of an originary trace or arche-trace. Yet we know that the concept destroys its name and that, if all begins with the trace, there is above all no originary trace". Véase, of Grammatology, trans. Gayatri Chakravorty Spivak (Baltimore: Johns Hopkins University Press, 1977) 61.

1 Estamos conscientes de que Carpentier participó en el movimiento surrealista y después lo abandonó. No obstante, su contacto con Breton y otros surrealistas permitio que desarrollara un interés más profundo en la cultura africana, algo que él ya había iniciado en Cuba. Incluso, Carpentier, en un momento, fue defensor del surrealismo. Véase, González Echevarría, 58-59.
} 
una llama crecida por el pelo encendido ahogaba su último grito. Cuando las dotaciones se aplacaron, la hoguera ardía normalmente, como cualquiera hoguera de buena leña, y la brisa venida del mar levantaba un buen humo hacia los balcones donde más de una señora desmayada volvía en sí. Ya no hab́a nada que ver.

La diferencia entre las dos interpretaciones se relaciona directamente con la cultura y la religión de los que presencian la ejecución de Mackandal: los blancos son testigos de la muerte de Mackandal y los negros de su salvación. La polaridad entre un grupo y el otro se reproduce en los dos párrafos separados por "Mackandal sauvé". El primero contiene la versión negra y el segundo la blanca; los negros vieron vida y los blancos muerte.

El tiempo que presenciamos en "Viaje a la semilla" y El reino de este mundo aparenta ser histórico. El cuento narra la vida y muerte del Marqués de Capellanías. La novela comienza con Mackandal, en 1750 y termina después del gobierno de Boyer, en la tercera década del siglo diecinueve. Sin embargo, hay otro tiempo que niega el primero y responde, no a una estructura cronológica, sino a una que es cíclica y se asocia-con la religión africana. El último capítulo, "Agnus Dei", muestra que nada ha cambiado. Si al comienzo de la novela Monsieur Lenormand de Mesy oprime a sus esclavos y éstos luchan para liberarse de él, al final de la lectura notamos que los mulatos son los nuevos opresores y Ti Noel continuará la lucha encabezada por Mackandal, Bouckman y otros. La cultura europea busca la dominación de los negros y los negros luchan para liberarse de ella. A pesar de su presencia en el Caribe, las culturas blancas y negras siempre se mantendrán distantes. (Obviamente, esta estructura trasciende el color de la piel de los protagonistas, como podemos notar con Christophe y los mulatos republicanos.)

Si El reino de este mundo yuxtapone el tiempo histórico al tiempo representado por la religión africana, esa misma estructura está presente en "Viaje a la semilla", con una pequeña diferencia; el ciclo religioso de la novela se convierte en un tiempo regresivo en el cuento. Como el aspecto africano en la novela, en "Viaje a la semilla" la estructura retrógrada niega el order histórico del reloj. Los dioses africanos controlan la narración: ellos están presentes en ambas obras y representados por el viejo negro, en el cuento, y por Mackandal, en la novela. Aunque Carpentier tenía cierto conocimiento de la religión afro-cubana, como notamos en jEcue Yamba O! (1933) y "Histoire de lune", (1933)6 , en Haití fue testigo del vudú. Estando en Haití, es probable que Carpentier conociera So Spoke the Uncle de Jean Price Mars. De acuerdo con los estudios de Price Mars,

\footnotetext{
${ }^{5}$ El reino de este mundo (Mexico: compañia General de Ediciones, 1971) 65-66.

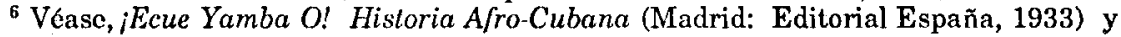
"Histoire de lunes", Cahiers de Sud (Paris), 157 (diciembre, 1933): 747-59. Este cuento se ha traducido al ingles y anotado por José Piedra con el título "Tale of Moons", en Latin American Lilerary Review 8, 16 (1980): 63-86.
} 
"Vodoun", de donde se deriva la palabra vudú, revela que el hombre no tiene libre albedrio, sino que es instrumento de Makou, el ser supremo. Nada ocurre sin la participación y la voluntad de los espíritus, el Vodoun. Price Mars explica: "The Vodoun are embodied in human beings whom they use to make known their wishes as well as in natural phenomena which represent manifestations of their anger, vengeance, and power" ${ }^{m 7}$. Ahora podemos entender las palabras de Bouckman, las mismas que ambos Price Mars y Carpentier reproducen en sus textos. Dice Carpentier en la novela: "El Dios de los blancos ordena el crimen. Nuestros dioses nos piden venganza. Ellos conducirán nuestros brazos y nos darán la asistencia. Rompan la imagen del Dios de los blancos, que tiene sed de nuestras lágrimas; escuchemos en nosotros mismos la llamada de la libertad!". La lucha de lo africano contra lo europeo ha sido provocada por los dioses y manifestada por los hombres.

Al igual que El reino de este mundo, "Viaje a la semilla" contiene dos textos Y, por lo tanto, ofrece dos lecturas: una se ajusta al mundo europeo y la otra al africano. Este último es menos evidente pero, como en la novela, controla la acción. Está presente desde el comienzo de la narración, con el negro viejo que pone en marcha el tiempo regresivo (secciones I y II), con la negra vieja que le murmura a la Marquesa que desconfie de los ríos y de lo verde que corre (sección

${ }^{7}$ So Spoke the Uncle, traduccion de Magdaline W. Shannon (Washington, DC: Three Continents Press, 1983) 97-98.

8 Igual que Carpentier, Price Mars escribe:

Good Lord who made the sun

Which shines on us from on high,

Who raises the sea,

Who makes the tempest roar,

Hear you, people, the Good Lord

Is hidden in his cloud.

From there he looks down on us

And sees all that the white men do.

The God of the white men commands crime,

Ours solicits god deeds,

But this God who is so good (ours) Orders us to vengeance.

He will guide our hand.

And give us assistance.

Break the image of the god of the white men

Who has thirst for our tears

Hear in our heart the call of liberty (48, nota 22$)$.

La misma cita también se reproduce en el libro de Victor Schoelcher, Vie de Toussaint. Louverture, publicado en 1889 .

- La fusión de los dos tiempos contradictorios de las culturas africanas y curopeas también se expresa por medio de la palabra. Tenemos un indicio de la unión de lo opuesto con lo que en poesía llamariamos un oxímoron. En el cuento encontramos los siguientes ejemplos: "Como era costumbre, los esposos fucron a la iglesia para recobrar su libertad" (88) y "Cuando el médico movió la cabeza con desconsuelo profesional, el enfermo se sintió mejor" (82). Todas las citas son de Guerra del tiempo (México: Compañía General de Ediciones, 1970). 
IV), con los Cabildos de Arará y la negra de entrecanás (sección VI) con el negro Eligio, que le pide a Marcial, niño, que se lave las manos (sección VIII), y, finalmente, con Melchor (secciones IX y X). Es decir, el mundo negro africano está presente desde el principio hasta el final, o, teniendo en cuenta la estructura retrógrada de la narración, desde el final hasta el principio.

Obviamente, el negro viejo es un cura de una religión africana. Ysi Antonio Benítez Rojo propone que el negro habla un lenguaje incomprensible porque habla al revés ${ }^{10}$, nosotros pensamos que, de acuerdo con nuestra interpretación, el negro está hablando el lenguaje de su religión africana. La incomprensión se debe a un narrador de origen europeo que no entiende o interpreta lo africano, sino que sólo lo describe. La falta de entendimiento se relaciona con otro incidente, casi idéntico, en la sección X, enlazando al negro viejo y a Melchor. Es probable que el negro viejo sea Melchor ${ }^{11}$. El narrador nos dice lo siguiente acerca del habla del negro joven: "Melchor sabía canciones fáciles de aprender", porque las palabras no tenian significado y se repetian", p. 100. Para el narrador que desconoce la religión africana, las palabras sin significado de Melchor equivalen al lenguaje incomprensible del negro viejo.

"Viaje a la semilla" niega el tiempo cronológico para regresar a un tiempo anterior a la presencia de la civilización occidental en América. El mundo africano se asocia con el origen, pero el mundo occidental también lo fue en un pasado $^{12}$. A medida que la narración va hacia el principio, en la sección XI presenciamos una armonía entre el marqués, niño, y su perro.

La sección anterior describe justamente a Melchor y al reino africano, donde se menciona que Melchor había nacido en Africa, era nieto de príncipes y habia vivido en un mundo de armonía entre los hombres y los animales. En ese pasado también notamos la unión entre Melchor y Marcial: ambos son jóvenes, ambos son traviesos y ambos tienen secretos. Si esta sección muestras como habíamos dicho, la unión entre Melchor y el pasado africano, donde el animal es un elemento importante, la siguiente se describe casi de la misma manera, pero esta vez narra el mundo entre Marcial y Canelo. Estas dos escenas se relacionan con la descripción del mundo africano en $E l$ reino de este mundo, cuando Ti Noel recuerda los cuentos de Mackandal y que los reyes africanos vivían en armonía con los animales ${ }^{13}$. Además, la escena entre Marcial y Canelo

\footnotetext{
${ }^{10}$ Antonio Benitez Rojo, "Viaje a la semilla', o el texto como espectáculo", Discurso Literario, 3, 1 (1985): 53-74.

${ }^{11}$ Esta idea también se expresa en los estudios de Frank Janney, "Alejo Carpentier and His Early Works (London: Tamesis, 1981), 90 y de Eduardo González, "Viaje a la semilla" y El siglo de luces: conjugación de dos textos", Revista Iberoamericana, 41 (1975): 423 43. Para una interpretación del viejo negro como representante de la religión africana, véase: Janney, 90 y Benítez Rojo, 62.

${ }^{12}$ Es aquí donde notamos un tema que después se relacionará con el momento antes de la llegada de los españoles en Los pasos perdidos de Carpentier. Véase, Los pasos perdidos (México: Edición y Distribución Iberoamericana de Publicaciones, 1953).

${ }^{13}$ El reino de este mundo, 27-29.
} 
se va a repetir en otra en la que Marcial también está presente. Nos referimos a una escena en "Los fugitivos", cuento que se publica dos años después de "Viaje a la semilla", en 1946. Como en el primer cuento, en el segundo, Cimarrón y Perro se alejan de la civilización y regresan a un origen, es decir, a un estado anterior al mundo occidental, representado por la naturaleza ${ }^{14}$. En este mundo primitivo, Cimarrón se convierte en (un) perro. En Viaje a la semilla también existía una identidad entre el hombre y el animal. Como Cimarrón, Marcial, niño, actúa como un perro:

Canelo y Marcial orinaban juntos.... Ambos comran tierra, se revolcaban al sol, bebian en la fuente de los peces, buscaban sombra y perfume al pic de las albahacas. En horas de calor, los canteros húmedos se llenaban de gente. Ahi estaba la gansa gris, con bolsa colgante entre las patas zambas; el gallo viejo del culo pelado; la lagartija que decía "urí, urá", sacándose del cuello una corbata rosada; el triste jubo, nacido en ciudad sin hembras; el ratón que Lapiaba su agujero con una semilla de carey. Un día, señalaron el perro a Marcial.

-Guau, guau! — dijo.

Hablaba su propio idioma. Había logrado la suprema libertad (103-104).

La libertad de Marcial equivale al mundo africano; se asocia con la inocencia del niño y con un tiempo anterior a la historia y presencia del mundo contemporáneo. Para Marcial, este otro mundo sólo se logra por medio del viaje a la semilla. Sin embargo, el proyecto de Carpentier de negar la historia, en cierto sentido, fracasa. El regreso de Marcial y Melchor a un tiempo antes de la indoctrinación de la cultura occidental sólo lo presenciamos en el texto, en la escritura. Es decir, si el tiempo que corresponde a la religión africana subvierte el tiempo cronológico, la misma estructura retrógrada del cuento no existe ni en el espacio ni en el tiempo, sino en la página y se limita a la palabra y la ficción. No obstante, el movimiento hacia un principio continúa desmantelando la cultura occidental y problematiza el principio de una narración, basado, otra vez, en lo que Carpentier asocia con el mundo africano.

"Viaje a la semilla" empieza con los obreros y la destrucción de la casa del Marqués de Capellanías. Pero el comienzo cronológico del cuento no se encuentra en las primeras páginas, sino al final, es decir, con el embarazo de la madre de quien será Marcial, el futuro Marqués de Capellanías. "Viaje a la semilla" propone, no sólo la inversión del tiempo sino también de la estructura de narrar. El final debería ser, no la concepción del niño, sino la muerte del marqués, seguido por los obreros y la destrucción de la casa. En este sentido, el cuento cuestiona, e incluso niega, el origen de su propia narración. El comienzo del cuento no es el producto de un principio, sino de un final. Aunque el origen existe como momento único e independiente, posiblemente como

14 Véase: "Los fugilivos", El Nacional, 4 de agosto (1946): 9. 
resultado de una trayectoria histórica que después se une al tiempo, sólo podemos entender ese momento dentro del contexto de los eventos que le siguen. En otras palabras, el momento de modernidad cobra importancia, no como un instante aislado que privilegia un momento por encima de otros, sino como parte de la secuencia histórica ${ }^{15}$. El nacimiento del Marqués de Capellanías se entiende en relación a su fracaso económico y, finalmente, su muerte ${ }^{16}$. Por lo tanto, el origen o el principio es más bien producto, no de un comienzo, sino de un presente o un futuro. Sin embargo, lo contrario también es cierto. El viaje a la semilla también representa una negación de los eventos históricos para privilegiar un principio. En otras palabras, la muerte, el matrimonio del marqués y su niñez, no cobran sentido sin entender ese momento sagrado que le dio origen a las cosas. En realidad, el cuento contiene una doble estructura que por su propia existencia cuestiona la dominación singular de cualquiera de las dos que se postule como momento único. Esta idea se sobrentiende al final del cuento. La sección XIII cierra un ciclo y abre otro y corresponde a un principio y a un final, el final del cuento. Es decir, èl regreso de los trabajadores se encuentra al final del cuento, pero también, cronológicamente, nos remonta al principio y, por lo tanto, al ser el evento más reciente, es también el principio del cuento.

Anteriormente habiamos visto que el cuento contiene dos interpretaciones. Ahora esa misma observación nos ayuda a entender que el cuento tiene dos principios y dos finales, el físico y el cronológico. Así, pues, el cuento propone varias lecturas: una sería tradicional y comienza con la sección I y termina con la sección XIII, la última. La otra también sería tradicional en cuanto a que es una lectura cronológica. Pero en vez de comenzar con la sección I, empieza con la sección XII, el nacimiento del Marqués, y termina con la sección I, su muerte, y la sección XIII, la destrucción de la casa. Más correcto, comienza con la última oración de la sección XII y nos obliga a leer al revés, hacia el final o, mejor dicho, hacia el principio ${ }^{17}$. Esta segunda lectura también sería un viaje a la semilla, es decir, hacia el principio físico de la narración, el que comienza en las primeras páginas del cuento. Pero tanto como nos conduce al principio, también nos conduce al final, a la muerte. Además, es probable que el cuento se haya escrito al "derecho" y se haya organizado "al revés".

\footnotetext{
16 Véase, Paul de Man, "Literary History and Literary Modernity", en Blindiness and Insighl (New York: Oxford Univeristy Press, 1971) 142-65.

${ }^{16}$ Donald Shaw y Manuel Durán caen en la trampa de asociar el viaje a la semilla con la ruina económica del marqués y la falta de autenticidad de su persona, como comentario político de Carpentier. Véase: Alejo Carpentier (Boston: Twayne Publishers, 1985) 24 y Durán, 82-84. Estamos de acuerdo con Carlos Alonso cuando afirma que el compromiso político de Carpentier está ausente en esta obra. Véase su 'Viaje a la semilla': historia de una entelequia", Modern Language Notes, 94, 2 (1979): 386-393.

${ }^{17}$ Nuestro análisis equivaldría a u na lectura a la Rayuela, donde el lector ya no es pasivo sino activo. En este sentido, es posible que "Viaje a la semilla" sea un cuento precursor a la novela de Cortázar. Rayuela (Buenos Aircs: Editorial Sudamericana, 1963).
} 
Al problematizar el principio, que también es el final, el cuento de Carpentier sugiere las preocupaciones de Giambattista Vico, y más especificamente de Vico por medio de Edward Said en su libro Beginnings. Asi como la negra vieja prevé la situación de la marquesa, Carpentier hace lo mismo con el estudio de Said. Aunque éste privilegia el comienzo de una actividad y explora las consecuencias de la misma, el principio, para él, no es una sucesión en el tiempo sino, algo más. Esta idea queda clara cuando dice Said:

"that beginnings are first and important but not always evident, that beginning is basically an activity which ultimately implies return and repetition rather than simple linear accomplishment, that beginning and beginningagain are historical whereas origins are divine, that a beginning not only creates but is its own method because it has intention"18.

Si Said favorece el principio como punto de partida, el cuento de Carpentier justifica esta jdea, pero también la invierte para postular el final como otro momento privilegiado. Y si Vico considera las culturas romana y griega como elemento fundamental para entender la historia y el pensamiento occidental y Said hace lo mismo con la presencia francesa y europea en la crítica contemporánea para formular sus ideas, Carpentier, basándose en lo que para él es la tradición africana, propone que dentro de la sociedad americana y caribeña el principio y el final tienen una función dialéctica.

Para Vico y Said la historia es cíclica y se desplaza de la "edad de los dioses", a la "edad de los héroes", a la "edad de los hombres". Vico también previó la repetición de la historia. Si las tres edades representan el corso que siguen las naciones, el ricorso es un segundo ciclo, una resurreción que las naciones experimentan. Pero el ricorso no es una mera repetición del corso de las naciones; es un proceso histórico que se le ha concedido al corso para rectificar los errores del pasado y trascender el "barbarism of reflection" de la malicia premeditada y regresar al "barbarism of sense", a un estado primitivo donde el hombre vuelve a ser religioso, veraz y fiel' ${ }^{19}$. El cuento de Carpentier se ajusta a las mismas necesidades de corregir la historia. El retorno al principio repre-

\footnotetext{
${ }^{18}$ Beginnings: Intention and Method (New York: Basic Books, 1975), xiii. Said define la intención de la siguente manera: "By intention I mean an appetite at the beginning intellectually to do something in a characteristic way -either consciously or unconsciously, but at any rate in a language that always (or nearly always) shows signs of the beginning intention in some form and is always engaged purposefully in the production of meaning. With regard to a given work or body of work, a beginning intention is really nothing more than the created inclusiveness within which the work develops" (12). La idea de principios y su desplazamiento hacia la diferencia se ha visto en las ideas de Vico y también en las de Derrida. Said reconoce esto cuanto dice: "To bury, in Vico's sense, is to engender difference; and to engender difference, as Derrida has argued, is to defer presence, to temporize, to introduce absence" (373).

${ }^{19}$ The New Science, traduccion de Thomas Goddard Bergess y Max Harlod Fisch (Ithaca, NY: Cornell University Press, 1984).
} 
senta una manera de borrar o negar la historia y regresar a un momento antes de su comienzo porque la historia se equivocó. La presencia del europeo en el Nuevo Mundo dio como resultado la masacre de los indios caribeños y la esclavitud del africano. Este fue el comienzo de la historia en el Caribe, se desarrolla hasta el momento de la escritura del cuento y continúa hasta nuestros días. El viaje hacia el principio es una manera de comenzar otra vez, de permitir que los errores del pasado se eviten y proponer una historia de armonía entre el hombre y las cosas. Dentro del cuento, el regreso sería una manera de rectificar la dominación racial del blanco sobre el negro, las malas inversiones del marqués o su posible asesinato de la Marquesa de Capellanías ${ }^{20}$.

"Viaje a la semilla" representa la conjunción de lo opuesto, del blanco y el negro, de las culturas africanas y europeas, del tiempo histórico y el tiempo regresivo, del principio y el final de la narración. Es con esta idea de la unión de un presente y un pasado, de un principio y un final con la que podemos entender el final de la narración o, mejor dicho, su principio. Todo culmina en la sección XIII, al principio-final (o "fincipio") del cuento. Recordemos que en este capítulo, los trabajadores regresan al día siguiente ${ }^{21}$ y encuentran el trabajo acabado, detalle que le da valor a la corriente africana del cuento no como imaginación, sino como realidad. Aunque el viejo negro no es un personaje en esta última sección, hay huellas de su presencia. Perolo más importante ocurre cuando los obreros se sientan en los bancos y uno recuerda "la historia, muy difuminada, de una Marquesa de Capellanías, ahogada, en tarde de mayo, entre las malangas del Almendares"(107). Nos interesa el recuerdo de la muerte de la marquesa. El recuerdo, como la muerte de la marquesa, tiene su importancia. en un momento determinado, en un pasado cuando ella y el marqués vivían juntos y la negra vieja le aconsejó que tuviera cuidado con los ríos. Sin embargo, el recuerdo no es producto de un pasado, sino de un presente; no de un principio, sino de un final. La conmemoración, como el recuerdo, corresponde a las exigencias del pasado, pero también a las necesidades de una sociedad contemporánea. Dice Eugene Vance:

By "commemoration" I mean any gesture, ritualized or not, whose end is to recover, in the name of a collectivity, some being or event either anterior in time or outside of time in order to fecundate, animate, or make meaningful a moment in the present. Commemoration is the conquest of whatever in society or in the self is perceived as habitual, factual, static, mechanical, corporeal, incrt, worldly, vacant, and so forth ${ }^{22}$.

\footnotetext{
${ }^{20}$ Véase, por ejemplo, Shaw, 24 y Durán, 81-82.

${ }^{21}$ El cuento se narra en doce horas. Véase, Cronzález Echevarría, "Isla a su vuelo fugitiva: Carpentier y el realismo mágico", Revista Iberoamericana, 40 (1974): 58.

22 "Roland and the Poetics of Memory," en Textual Strategies, ed. Josue Harari (Ithaca, NY: Cornell University Press, 1979) 374-75.
} 
Carpentier está consciente de que el recuerdo es una recuperación del pasado. En una entrevista con Mario Vargas Llosa, Carpentier asocia el concepto de memoria con la recuperación de la juventud. Dice lo siguiente:

Una preocupación de largo tiempo ha sido la identidad que existe entre la extrema infancia en recuperar una especie de no-conocimiento por el que uno ha pasado. Es decir, yo no soy el mismo hombre que era a los veinte años. Por lo tanto, si miro mis veinte años desde la edad de sesenta que acabo de cumplir, pues he ido adquiriendo cosas que han modificado mi vida, $y$ lo interesante ... es el retroceso, es decir, cómo era en aquella época, cuando no conocía tal literatura .... Por lo tanto me parece que la técnica del hombre que escribe memorias y quiere empezar por el principio y llegar hasta hoy es completa. mente falsa ${ }^{23}$.

Después afirma que la memoria es una obsesión que aparece en Los pasos perdidos y "Viaje a la semilla". El presente estimula el proceso de recordar, obligando a que la imagen del pasado se ajuste, no al momento sagrado ya perdido para siempre, sino a la realidad contem poránea. Tengamos en cuenta que el principio y el final se vuelven a unir por medio del recuerdo. En el cuento, la destrucción de la casa pone en marcha el recuerdo de la muerte de la Marquesa de Capellanías ${ }^{24}$. La misma destrucción también estimula el re. cuerdo del viejo y da comienzo a nuestra lectura del cuento. El recuerdo del viejo, al principio, y el recuerdo del obrero, al día siguiente, abre y cierra el pasado del marqués y la marquesa; abre y cierra el Viaje a la semilla. El recuerdo une al negro viejo y al trabajador, a ellos y a nosotros. El pasado, como el principio cronológico del cuento, se ha perdido para siempre. Sólo existen las huellas de ese momento original, del cuento, el que llevamos en la memoria, nuestro recuerdo.

\footnotetext{
${ }^{23}$ Vease: "Cuatro preguntas a Alejo Carpenticr", Marcha, 1246, 12-III (1963): 32. Tambión citado por Janney, 6.

${ }^{24}$ La última frase del cuento es importante. Hay una unidad estructural entre la muerte de la marquesa y la palabra muerte que aparece al final del párrafo. Aunque es posible que el marqués o Melchor hayan matado a la marquesa, desde el presente de los obreros, es el tiémpo el que provoca la muerte de la marquesa y el marqués. Es decir, el momento de nacer y vivir, que equivale a entrar en el tiempo, es lo que nos lleva a la muerte.
} 